\title{
Prevalence and Correlates of Dyslipidemia among Adults in Saudi Arabia: Results from a National Survey
}

\author{
Abdulaziz F. Al-Kaabba, Nasser A. Al-Hamdan, Ahmed El Tahir, Abdelshakour M. Abdalla, \\ Abdalla A. Saeed, Muaawia A. Hamza* \\ Faculty of Medicine, King Saud Bin AbdulAziz University for Health Sciences, King Fahad Medical City, Riyadh, \\ Saudi Arabia \\ Email: "
}

Received September 10, 2012; revised October 12, 2012; accepted November 13, 2012

\begin{abstract}
Data were collected and analyzed from a cross-sectional study using the World Health Organization's STEPwise approach, to estimate the prevalence of various types of dyslipidemia and determine their associated factors among adults in Kingdom of Saudi Arabia. The study population included 4490 Saudi adults aged 15 years and older who were selected by a stratified, multistage, cluster random sampling technique. Lipid profile was determined by spectrophotometrically by biochemical methods, high total cholesterol (TC) was defined as TC of $5.2 \mathrm{mmol} / \mathrm{L}$ or more, hypertriglyceridemia as serum triglycerides level $1.7 \mathrm{mmol} / \mathrm{L}$ or more and low high-density lipoprotein cholesterol (HDL-C) as serum HDL-C $0.9 \mathrm{mmol} / \mathrm{L}$ or less, LDL-C $3.35 \mathrm{mmol} / \mathrm{L}$ or more and TC/HDL ratio 5 or more. Of the 4490 subjects ( $94.4 \%$ of total sample) included in the final analysis, $51 \%$ were females, $23 \%$ of study subjects were less than 25 years and $11 \%$ were 55 or more years of age. The overall prevalence of dyslipidemia ranged from about $20 \%$ to $40 \%$. The highest prevalence was for triglycerides where about $44 \%$ of all subjects were affected. About a fifth of the subjects had high level of total cholesterol. Males had significantly higher prevalence of all types of dyslipidemia than female except LDL-C and TC. Higher dyslipidemia prevalence of total cholesterol and triglycerides were significantly found in older subjects, illiterates and housekeepers. Lower prevalence rates for HDL-C was significantly observed in retired and youngest subjects. There were significant regional variations and significantly higher prevalence of dyslipidemia among hypertensives, diabetics, obese/overweight, smokers and physically inactive subjects. There were no significant differences according to income or fruits and vegetable consumption. Logistic regression analysis revealed that obesity/overweight, gender, age, diabetes were the most important significant predictors of dyslipidemia. The findings of this study suggest that the prevalence of dyslipidemia is high in Saudi Arabia. Multisectorial intervention strategies are needed targeting the predictors and significant risk factors identified.
\end{abstract}

Keywords: Dyslipidemia; Prevalence; Risk Factors; Adults; Saudi Arabia

\section{Introduction}

Dyslipidemia is one of the most important risk factors for many chronic non-communicable diseases resulting in serious morbidity, and mortality, and medical costs worldwide [1-3]. This situation has become apparent in the Kingdom of Saudi Arabia (KSA), given the economic growth and associated sociodemographic, dietary, and lifestyle changes in recent decades coupled with a reduced burden of infectious diseases [4]. The prevalence of dyslipidemia varies according to the ethnic, socioeconomic, and cultural characteristics of distinct population groups.

Assessing the prevalence, risk factors, and predictors of this condition is of paramount importance for pre-

"Corresponding author. venting and controlling the disease and its sequellae. A few studies have recently addressed these issues in the KSA [5-8]. Due to the dramatic increases in the prevalences of both obesity and type 2 diabetes mellitus, which are linked to changes in lifestyle associated with modernization and socioeconomic development, adverse changes in the profile of blood lipids are not unexpected.

This study attempts to estimate the prevalence and patterns of serum lipid profiles and associated factors in Saudi adults.

\section{Subjects and Methods}

This is a cross-sectional community-based study covering the whole population of KSA in 2005. The World Health Organization's STEPwise approach to Surveillance (STEPS) of Non-Communicable Diseases (NCD) 
risk factors was the basis for conducting the survey and for collecting the data $[9,10]$.

\subsection{Study Population}

All Saudi population from all the 20 health regions of the country aged 15 - 64 years was involved.

\subsection{Sampling}

A multistage stratified cluster random sampling technique was used to recruit the study subjects. Stratification was based on age (5 - 10 year age groups) and gender (Male/female 2 groups). All health regions of the country (20 regions) were covered. Based upon proposed methodology of the WHO STEPwise approach a sample size of 196 was calculated for each of these ten strata. A list of all Primary Health Care Centers (PHCCs) in each region was prepared and $10 \%$ of these PHCCs were randomly chosen, and allocated regional sample to them proportionate to the size of their catchment population in sampled PHCCs. To identify the households a map of the health center coverage area was used to choose the houses. Each house was assigned a number and a simple random draw was made.

\subsection{Data Collection}

Data were collected using the WHO STEPwise approach $[9,10]$ which includes a questionnaire, physical measurements plus biochemical measurements covering hypertension and other chronic diseases and risk factors in addition to physical activity pattern, intensity and duration. The questionnaire was translated into Arabic by a team of physicians and was back translated to ensure the accuracy of translation. Arabic instrument was pre-tested and corrected before using on 51 eligible respondents for wording and understanding of the questions, and necessary adjustments were made in the instrument in light of the pre-test.

\subsection{Data Collectors}

Data was collected by 54 males and 54 female collectors who worked in teams. Each field team was made up of four persons: a male data collector, a female data collector, a driver and a female assistant. Data collection teams were supervised by a hierarchy of local supervisor, regional coordinators and national coordinator.

\subsection{Training of Data Collectors}

All individuals involved in data collection attended a comprehensive training workshop that included interview techniques, data collection tools, practical applications and field guidelines.

\subsection{Analytical Techniques}

$5 \mathrm{ml}$ of blood was collected in the morning after the participants had abstained from eating overnight. Sodium heparin was used as an anticoagulant, and the samples were centrifuged at $3000 \mathrm{X} \mathrm{rpm}$ for $15 \mathrm{~min}$ at $20^{\circ} \mathrm{C}$ to separate plasma. Aliquots were prepared for storage $\left(-20^{\circ} \mathrm{C}\right.$ or $\left.-80^{\circ} \mathrm{C}\right)$ until further analysis. Total cholesterol (TC), triglycerides, and glucose were measured with commercially available enzymatic colorimetric kits from QCA (Amposta, Spain). Seriscann Normal (ref 994148) (QCA, Amposta, Spain) was used for quality control measures. Plasma high-density lipoprotein cholesterol (HDL-C) levels were analyzed by enzymatic method after precipitating plasma reagents with phosphotungstic acid and magnesium and LDL-cholesterol (LDL-C) was calculated according to the Friedewald's formula. This equation calculates the concentration of LDL-C based upon the presence of total cholesterol, HDL and triglyceride levels: LDL $=$ total cholesterol - HDL - (triglycerides/5) [11]. Although this equation is fairly accurate, there are certain factors that could cause your LDL cholesterol levels to be incorrect by using this calculation. These would include triglyceride levels over $400 \mathrm{mg} / \mathrm{dL}$ and consuming a meal before having your cholesterol levels. The cut off levels were used according to the suggestions of the National Cholesterol Education Program-Adult Treatment Panel III [12].

\subsection{Data Management}

Questionnaires collected from the field were reviewed by team leaders assigned to each team before submitting them to the headquarters for data entry. Double entry of the questionnaires was performed using EPI-INFO 2000 software and EpiData software developed by the Menzes centre for validation. After data entry, data cleaning was conducted. New variables were defined by adopting the standard Steps variables (STEPS Data Management Manual, Draft version v1.5, October 2003).

\subsection{Statistical Analysis}

Descriptive statistics, t-test or Mann Whitney test and ANOVA or Kruskal Wallis tests were used as appropriate after checking for normality. Multiple logistic regressions for significant predictors were performed. Dyslipidemia was the dependent variable and all significant variables in bivariate analysis were the independent variables. Level of significance was set to be $<0.05$ throughout the study. The data were processed using SPSS version 17. Total frequency in some columns may vary due to missing data from certain variables.

\subsection{Ethical Clearance and Confidentiality}

The protocol and the instrument of the surveillance were 
approved by the Ministry of Health, Center of Biomedical Ethics and the concerned authorities in KSA. Informed consent of all subjects was obtained. Confidentiality of data was assured and that data will be used only for the stated purpose of the survey.

\section{Results}

Of the 4490 subjects $(94.4 \%$ of the total sample) included in the final analysis, 51\% were females, $23 \%$ were aged less than 25 years, and $11 \%$ were aged 55 years and older. Table 1 shows the mean concentrations of the lipid profile according to gender. Triglycerides and the ratio of total cholesterol (TC)/high-density lipoprotein (HDL-C) were significantly higher in males, while HDL-C and TC were significantly higher in females. No significant differences in low-density lipoprotein Cholesterol (LDL-C) concentration according to gender P. 0.341 .

The overall prevalence of the different types of dyslipidemia was according to sociodemographic characteristics appear in Table 2. The overall prevalence of all types of dyslipidemia was ranged from about $20 \%$ to $44 \%$. The highest prevalence was for triglycerides, where about $44 \%$ of all subjects were affected. More than $25 \%$ of the subjects exhibited low levels of HDL-C, and approximately one-fifth of the subjects had high levels of TC. Males had significantly higher prevalences of all types of dyslipidemia except cholesterol associated with LDL-C and TC. Prevalence of dyslipidemia increases with advancing age. These differences were significant for all types of dyslipidemia except cholesterol associated with HDL-C. Education level was also significantly

Table 1. Mean concentration of lipid profile according to gender.

\begin{tabular}{ccccccc}
\hline \multirow{2}{*}{ Sex } & & $\begin{array}{c}\text { TGs } \\
(\mathrm{mmol} / \mathrm{L})\end{array}$ & $\begin{array}{c}\mathrm{TC} \\
(\mathrm{mmol} / \mathrm{L})\end{array}$ & $\begin{array}{c}\text { HDL-C } \\
(\mathrm{mmol} / \\
\mathrm{L})\end{array}$ & LDL-C & $\begin{array}{c}\text { TC/HDL } \\
\text { ratio }\end{array}$ \\
\hline \multirow{2}{*}{ Male } & $\mathrm{N}$ & 2178 & 2198 & 2198 & 2176 & 2196 \\
& $\mathrm{SD}$ & 1.07 & 1.14 & 0.81 & 1.21 & 2.35 \\
& Mean & 1.50 & 4.51 & 1.45 & 2.76 & 3.77 \\
Female & $\mathrm{N}$ & 2267 & 2291 & 2291 & 2265 & 2290 \\
& $\mathrm{SD}$ & 0.83 & 1.20 & 0.79 & 1.19 & 2.14 \\
& $\mathrm{Mean}$ & 1.63 & 4.47 & 1.37 & 2.78 & 4.08 \\
Total & $\mathrm{N}$ & 4445 & 4489 & 4489 & 4441 & 4486 \\
& $\mathrm{SD}$ & 0.96 & 1.17 & 0.81 & 1.19 & 2.26 \\
& & & & & & \\
P-value & & $<0.001$ & 0.014 & $<0.001$ & 0.341 & $<0.001$ \\
\hline
\end{tabular}

associated with dyslipidemia prevalence. Illiterates showed the highest prevalence for TC, triglycerides, and LDL-C. Significant regional variations emerged from the data; the North region was associated with the highest prevalence of triglycerides, while the Eastern region reported the highest low levels of HDL-C. Housekeepers were associated with a significantly higher prevalence of dyslipidemia, while students had the lowest prevalence rates. Income was not significantly associated with any type of dyslipidemia.

Calculations of the prevalence of dyslipidemia according to co morbidity, with odds ratios and $95 \%$ confidence intervals reported in Table 3. All types of dyslipidemia except low HDL-C were significantly associated with the presence of hypertension, diabetes mellitus, and obesity/overweight.

Dyslipidemia was affected by lifestyle (Table 4); smoking and lower physical activity were significantly associated with some types of dyslipidemia. There were no significant differences associated with the consumption of fruits and vegetable.

A logistic regression analysis was performed for significant predictors (Table 5). All significant variables in Tables $\mathbf{2}$ and $\mathbf{3}$ were included in the regression model. Obesity/overweight was a significant predictor for all types of dyslipidemia. Gender was a significant predictor for all dyslipidemia types except LDL-C, while age was significant for all types except HDL-C. Diabetes mellitus was a significant predictor for all dyslipidemia types except HDL-C and LDL-C. Occupation and hypertension co morbidity were not significant predictors for any of the types of dyslipidemia.

\section{Discussion}

As demonstrated in the current study, the prevalence of dyslipidemia among adults in the KSA ranges from $20 \%$ to $44 \%$, which is comparable to the prevalences reported in previous studies [5-8]. Reported rates of dyslipidemia ranged from $2.7 \%$ to $51.9 \%$ in several studies worldwide [13-24]. This relatively large range in recent years may be due to socioeconomic status, genetic races or to differences in definitions, methodologies, and study populations. The TC/HDL-C and LDL-C/HDL-C ratios are good predictors of a positive response to lipid-lowering intervention [23]. This study showed that more than $30 \%$ of males have a mean TC/HDL-C of $4.39 \pm 2.35$, with the highest levels occurring between ages $45-54$ years, indicating that this group is at higher risk of developing coronary disease. There was no significant statistical difference in the prevalence of high LDL-C levels between men and women, which is consistent with other studies [24,25].

Interestingly, this study revealed higher TC and HDL 
Table 2. Prevalence of dyslipidemia according to subject's demographics \% (n).

\begin{tabular}{|c|c|c|c|c|c|}
\hline Demographics & $\begin{array}{l}\text { Hypercholesterolemia } \\
\quad>-5.2 \mathrm{mmol} / 1\end{array}$ & $\begin{array}{c}\text { Hypertriglyceridemia } \\
>-1.27 \mathrm{mmol} / 1\end{array}$ & $\begin{array}{l}\text { Low HDL-C } \\
<-0.90 \mathrm{mmol} / 1\end{array}$ & $\begin{array}{l}\text { LDL-C } 3.35 \\
\mathrm{mmol} / 1\end{array}$ & TC/HDL Ratio $>-5$ \\
\hline \multicolumn{6}{|l|}{ Gender } \\
\hline Male & $18.7(411)$ & $40.2(876)$ & $33.7(741)$ & 30.7 (659) & $30.6(672)$ \\
\hline Female & $19.9(455)$ & $28.8(652)$ & $17.7(405)$ & $29.8(662)$ & $17.5(400)$ \\
\hline P-value & 0.170 & $<0.001$ & 0.001 & 0.272 & $<0.001$ \\
\hline \multicolumn{6}{|l|}{ Age (Years) } \\
\hline $15-24$ & $7.0(69)$ & $19.9(190)$ & $25.6(251)$ & $13.6(127)$ & $15.4(150)$ \\
\hline $25-34$ & $16.0(168)$ & $29.8(311)$ & $26.7(280)$ & $26.6(272)$ & $21.8(229)$ \\
\hline $35-44$ & $22.3(248)$ & $38.2(422)$ & $24.3(271)$ & $35.0(37.8)$ & $25.1(239)$ \\
\hline $45-54$ & $27.9(228)$ & $44.0(359)$ & $25.3(207)$ & $41.5(334)$ & $31.2(25.5)$ \\
\hline $55+$ & $28.9(153)$ & $40.7(246)$ & $25.9(137)$ & $40.3(210)$ & $30.1(159)$ \\
\hline P-value & $<0.001$ & $<0.001$ & 0.804 & $<0.001$ & $<0.001$ \\
\hline \multicolumn{6}{|l|}{ Geographical region } \\
\hline East & $19.7(132)$ & $28.6(181)$ & $30.1(202)$ & $32.9(203)$ & $27.0(181)$ \\
\hline North & $24.2(96)$ & $54.2(215)$ & $24.2(96)$ & $27.4(101)$ & $26.6(105)$ \\
\hline South & $20.0(191)$ & $33.9(324)$ & $25.4(243)$ & $31.8(303)$ & $23.3(225)$ \\
\hline West & $18.2(261)$ & $33.2(477)$ & $26.0(373)$ & $33.9(483)$ & $25.5(366)$ \\
\hline P-value & 0.068 & $<0.001$ & 0.013 & $<0.001$ & 0.001 \\
\hline \multicolumn{6}{|l|}{ Education } \\
\hline Illiterate & $23.6(288)$ & $39.1(47.5)$ & $19.6(239)$ & $35.7(42.8)$ & $22.4(273)$ \\
\hline Primary & $21.7(250)$ & $36.2(412)$ & $25.7(296)$ & $33.9(380)$ & $25.4(292)$ \\
\hline Intermediate & $14.3(101)$ & $28.0(19.3)$ & $27.8(196)$ & $21.5(145)$ & $21.7(153)$ \\
\hline Secondary & $15.1(109)$ & $31.1(22.1)$ & $28.9(20.8)$ & $260(180)$ & $24.4(175)$ \\
\hline University + & $16.8(96)$ & $33.0(189)$ & $29.1(167)$ & $27.9(150)$ & $24.8(142)$ \\
\hline Vocational & $18.8(21)$ & $32.1(36)$ & $32.7(37)$ & $28.4(31)$ & $32.1(36)$ \\
\hline P-value & $<0.001$ & $<0.001$ & $<0.001$ & $<0.001$ & 0.096 \\
\hline \multicolumn{6}{|l|}{ Occupation } \\
\hline Government employee & $20.4(267)$ & $39.4(516)$ & $31.5(413)$ & $33.4(428)$ & $31.4(411)$ \\
\hline $\begin{array}{l}\text { Non-government } \\
\text { employee }\end{array}$ & $21.0(88)$ & $36.1(149)$ & $29.1(122)$ & $30.6(125)$ & $25.3(106)$ \\
\hline Self employed & $5.7(34)$ & $19.9(115)$ & $27.7(164)$ & $12.6(71)$ & $16.2(96)$ \\
\hline Student & $22.2(370)$ & $32.5(508)$ & $17.5(291)$ & $32.9(535)$ & $18.7(311)$ \\
\hline Housekeeping & $28.0(84)$ & $50.3(151)$ & $30.0(90)$ & $39.7(11.7)$ & $33.1(99)$ \\
\hline Retired & $11.8(23)$ & $31.2(59)$ & $33.2(65)$ & $24.3(45)$ & $25.1(49)$ \\
\hline P-value & $<0.001$ & $<0.001$ & $<0.001$ & $<0.001$ & $<0.001$ \\
\hline \multicolumn{6}{|l|}{ Monthly income } \\
\hline$<3000$ Saudi Riyals & $19.8(282)$ & $33.2(467)$ & $23.6(337)$ & $31.2(433)$ & $23.5(334)$ \\
\hline$<7000$ & $19.8(190)$ & $34.6(330)$ & $25.8(24.8)$ & $29.9(279)$ & $23.1(222)$ \\
\hline$<10000$ & $17.6(219)$ & $35.8(438)$ & $26.7(331)$ & $29.1(349)$ & $23.9(296)$ \\
\hline$<15000$ & $20.5(87)$ & $37.0(157)$ & $28.7(122)$ & $31.5(131)$ & $29.6(117)$ \\
\hline $15000+$ & $20.1(43)$ & $30.2(64)$ & $29.9(64)$ & $33.8(71)$ & $29.0(62)$ \\
\hline P-value & 0.556 & 0.301 & 0.103 & 0.594 & 0.169 \\
\hline
\end{tabular}


Table 3. Dyslipidemia according to comorbidity with hypertension, diabetes, overweight/obesity.

\begin{tabular}{|c|c|c|c|c|c|}
\hline Comorbidity & $\begin{array}{c}\text { Elevated total } \\
\text { cholesterol N (\%) }\end{array}$ & High triglycerides N (\%) & Low HDL-C N (\%) & LDL-C N (\%) & $\begin{array}{c}\text { TC/HDL ratio } \mathrm{N} \\
(\%)\end{array}$ \\
\hline \multicolumn{6}{|l|}{ Hypertension } \\
\hline Yes & $147(282)$ & $226(43.6)$ & $139(26.7)$ & $194(38.3)$ & $158(30.4)$ \\
\hline No & $715(18.1)$ & $1299(33.2)$ & $1001(25.3)$ & $1121(29.2)$ & $910(23.1)$ \\
\hline OR $(95 \% \text { C.I. })^{*}$ & $1.78(1.45-2.19)$ & $1.55(1.29-1.87)$ & $1.07(0.87-1.32)$ & $1.50(1.24-1.82)$ & $1.46(1.19-1.78)$ \\
\hline P-value & $<0.001$ & $<0.001$ & 0.264 & $<0.001$ & $<0.001$ \\
\hline \multicolumn{6}{|l|}{ Diabetes mellitus } \\
\hline Yes & $219(31.7)$ & $342(49.5)$ & $179(25.9)$ & $268(39.6)$ & $212(30.8)$ \\
\hline No & $638(17.1)$ & $1147(30.8)$ & $958(25.7)$ & $1038(28.7)$ & $850(22.8)$ \\
\hline OR $(95 \% \text { C.I. })^{*}$ & $2.25(1.87-2.69)$ & $2.51(2.07-3.03)$ & $1.01(0.84-1.22)$ & $1.63(1.38-1.93)$ & $1.50(1.26-1.80)$ \\
\hline P-value & $<0.001$ & $<0.001$ & 0.476 & 0.001 & $<0.001$ \\
\hline \multicolumn{6}{|l|}{ Obesity } \\
\hline \multicolumn{6}{|l|}{ Overweight } \\
\hline Yes & $700(22.9)$ & $1213(40.0)$ & $822(26.9)$ & $1053(35.5)$ & $834(27.4)$ \\
\hline No & $164(11.6)$ & $311(22.4)$ & $316(22.4)$ & $262(19.1)$ & $232(16.5)$ \\
\hline OR $(95 \% \text { C.I. })^{*}$ & $2.26(1.89-2.72)$ & $2.32(2.00-2.68)$ & $1.28(1.10-1.48)$ & $2.34(2.01-2.73)$ & $1.91(1.63-2.25)$ \\
\hline P-value & $<0.001$ & $<0.001$ & 0.001 & $<0.001$ & 0.001 \\
\hline
\end{tabular}

OR $(95 \% \text { C.I. })^{*}=$ Odds Ratio $(95 \%$ Confidence Interval $)$.

Table 4. Prevalence of dyslipidemia according to some life style practices.

\begin{tabular}{|c|c|c|c|c|c|}
\hline Life style habit (N) & High total cholesterol N (\%) & $\begin{array}{c}\text { High } \\
\text { triglycerides N (\%) }\end{array}$ & Low HDL-C ${ }^{*}$ N (\%) & LDL-C N (\%) & TC/HDL Ratio N (\%) \\
\hline \multicolumn{6}{|l|}{ Physical activity } \\
\hline High (733) & $125(17.1)$ & $223(30.4)$ & $184(25.1)$ & $221(30.2)$ & $180(24.6)$ \\
\hline Low (3625) & $720(19.9)$ & $1272(35.1)$ & $941(26.0)$ & $1077(29.7)$ & $878(24.2)$ \\
\hline P-value & 0.043 & 0.012 & 0.333 & 0.443 & 0.449 \\
\hline \multicolumn{6}{|l|}{ Daily smoker } \\
\hline Yes (549) & $115(20.9)$ & $212(38.6)$ & $175(31.9)$ & $187(34.1)$ & $171(31.31)$ \\
\hline No (3809) & $730(19.2)$ & $1247(32.7)$ & $918(24.1)$ & $1099(28.9)$ & $853(22.4)$ \\
\hline P-value & 0.166 & 0.004 & $<0.001$ & 0.005 & $<0.001$ \\
\hline \multicolumn{6}{|l|}{$\begin{array}{c}\text { Daily fruits/vegetables } \\
\text { consumption }\end{array}$} \\
\hline Below 5 servings (4081) & $791(19.4)$ & $1437(35.2)$ & $1049(25.7)$ & $1219(29.9)$ & $988(24.2)$ \\
\hline 5 + servings $(270)$ & $61(22.6)$ & $96(35.6)$ & $80(29.6)$ & $89(33.0)$ & $76(28.1)$ \\
\hline P-value & 0.114 & 0.486 & 0.089 & 0.077 & 0.086 \\
\hline
\end{tabular}

${ }^{*}$ HDL-C = High Density Lipoprotein cholesterol; LDL-C = Low Density Lipoprotein cholesterol; TC = Total Cholesterol.

cholesterol levels in females versus males, reflecting socioeconomic and cultural status in these communities. There were significant regional variations in lipid profile in this study, which may be related to the level of urbanization and genetic variation. Migration to urban centers and adoption of a sedentary lifestyle is likely re- lated to rising lipid levels and prevalence of dyslipidemia [16]. Regional variations in the prevalence of dyslipidemia were previously reported in national and international studies [5-8,26,27] and may be due to other variables in addition to geographical location.

The associations between dyslipidemia and male 
Table 5. Logistic regression analysis for predictors of dyslipidemia prevalence.

\begin{tabular}{|c|c|c|c|c|c|c|c|c|c|c|}
\hline Lipid/predictors & Sex & Age & Edu. ${ }^{*}$ & Occ. ${ }^{*}$ & Region & Smoking & $\mathrm{PA}^{*}$ & $\mathrm{HBP}^{*}$ & $\mathrm{DM}^{*}$ & $\mathrm{BMI}^{*}$ \\
\hline \multicolumn{11}{|l|}{$\mathrm{TC}$} \\
\hline Odds ratio & 0.78 & 0.96 & 1.01 & 1.03 & 1.01 & 1.25 & 0.81 & 1.08 & 1.52 & 0.56 \\
\hline \multicolumn{11}{|l|}{ 95\% C.I. } \\
\hline Lower & 0.63 & 0.95 & 0.98 & 0.99 & 0.791 & 0.96 & 0.79 & 0.84 & 1.22 & 0.46 \\
\hline Upper & 0.96 & 0.97 & 1.02 & 1.07 & 1.28 & 1.63 & 1.27 & 1.38 & 1.98 & 0.69 \\
\hline P-value & 0.01 & 0.01 & 0.92 & 0.20 & 0.97 & 0.09 & 0.96 & 0.56 & 0.01 & 0.01 \\
\hline \multicolumn{11}{|l|}{$\mathrm{HDL}$} \\
\hline Odds ratio & 2.09 & 1.00 & 0.98 & 0.98 & 1.27 & 1.66 & 0.97 & 1.12 & 1.01 & 0.84 \\
\hline \multicolumn{11}{|l|}{ 95\% C.I. } \\
\hline Lower & 1.75 & 0.99 & 0.96 & 0.94 & 1.02 & 1.34 & 0.89 & .87 & 0.88 & 0.78 \\
\hline Upper & 2.50 & 1.01 & 0.99 & 1.01 & 1.58 & 2.04 & 1.08 & 1.43 & 1.37 & 0.91 \\
\hline P-value & 0.01 & 0.29 & 0.01 & 0.19 & 0.027 & 0.010 & 0.78 & 0.375 & 0.39 & 0.01 \\
\hline \multicolumn{11}{|l|}{ TG } \\
\hline Odds ratio & 1.74 & 0.979 & 1.008 & 0.98 & 0.89 & 1.26 & 0.96 & 0.99 & 1.64 & 0.71 \\
\hline \multicolumn{11}{|l|}{ 95\% C.I. } \\
\hline Lower & 1.47 & 0.973 & 0.993 & 0.95 & 0.87 & 1.02 & 0.87 & 0.79 & 1.34 & 0.66 \\
\hline Upper & 2.07 & 0.986 & 1.024 & 1.01 & 1.08 & 1.56 & 1.05 & 1.25 & 2.01 & 0.77 \\
\hline P-value & 0.01 & 0.001 & 0.291 & 0.347 & 0.257 & 0.029 & 0.432 & 0.96 & 0.01 & 0.01 \\
\hline \multicolumn{11}{|l|}{ LDL } \\
\hline Odds Ratio & 0.93 & 0.96 & 0.99 & 1.03 & 1.70 & 1.27 & 0.99 & 0.99 & 1.16 & 0.77 \\
\hline \multicolumn{11}{|l|}{ 95\% C.I } \\
\hline Lower & 0.78 & 0.96 & 0.98 & 0.993 & 1.38 & 1.02 & 0.90 & 0.79 & 0.94 & 0.71 \\
\hline Upper & 1.11 & 0.97 & 1.02 & 1.07 & 2.11 & 1.59 & 1.09 & 1.26 & 1.43 & 0.83 \\
\hline P-value & 0.42 & 0.01 & 0.871 & 0.122 & 0.001 & 0.037 & 0.819 & 0.89 & 0.15 & 0.01 \\
\hline \multicolumn{11}{|l|}{$\mathrm{TC} / \mathrm{HDL}$} \\
\hline Odds ratio & 1.85 & 0.98 & 0.97 & 1.01 & 1.492 & 1.54 & 0.99 & 1.12 & 1.26 & 0.77 \\
\hline \multicolumn{11}{|l|}{ 95\% C.I. } \\
\hline Lower & 1.54 & 0.98 & 0.97 & 0.98 & 1.193 & 1.24 & 0.89 & 0.88 & 1.02 & 0.71 \\
\hline Upper & 2.22 & 0.99 & 1.03 & 1.05 & 1.866 & 1.915 & 1.09 & 1.42 & 1.57 & 0.84 \\
\hline P-value & 0.01 & 0.01 & 0.09 & 0.57 & 0.001 & 0.01 & 0.08 & 0.36 & 0.03 & 0.01 \\
\hline
\end{tabular}

${ }^{*}$ Edu $=$ Education; ${ }^{*}$ Occ $=$ Occupation; ${ }^{*} \mathrm{PA}=$ Physical activity HBP $=$ Hypertension; $\mathrm{DM}=$ Diabetes mellitus.

gender and advancing age detected in this study are in agreement with previous studies in the KSA [5-8] and other population-based and hospital-based studies [19, 21-23]. While the exact mechanisms of the impact of age on lipid levels are unknown, they may be related to hereditary characteristics and degenerative processes. Males were significantly more affected by dyslipidemia than females in the present investigation. Previously, females were reported to be more affected than males in some studies $[22,28]$, while other studies did not uncover a significant statistical difference in the prevalence of high TC and high LDL-C between men and women $[16,17,26]$. These variations and apparent inconsistencies may be explained by the differential gender distribution 
of other risk factors among different communities.

The data from the current study are in agreement with previous studies in the KSA that showed that dyslipidemia was associated with education and occupation [5-8]. A higher education level was strongly associated with hypercholesterolemia and high LDL-C levels, even after adjusting for age and body mass index [23,27]. In contrast, the level of education was not associated with dyslipidemia [28], but exhibited a strong inverse association in other studies [28-30] in agreement with this study. One study hypothesized that the high prevalence of dyslipidemia in subjects with a low education level may result from risk factors such as stress, poor working conditions, poor nutritional habits, or greater difficulties in securing access to health care services [21].

The prevalence of dyslipidemia was significantly higher among housekeepers in this study, possibly due to constant exposure to food and lack of physical activity [21]. Previous studies reported that dyslipidemia rates were higher in men and women who described their occupation as administrative/management compared with those performing physical/labor positions [23]. Other studies, however, reported that, there was no significant association between occupational status and dyslipidemia [30]. These apparent inconsistencies may be due to the confounding effects of other risk factors. Smoking was significantly associated with dyslipidemia in this study, in agreement with other studies [23-25]. The risk of low HDL-C and TC/HDL-C was significantly higher in smokers in a logistic regression analysis [21]. There was no significant association between income and dyslipidemia in this study, consistent with a previous study [25]; other studies reported that household income was inversely related to the prevalence of dyslipidemia [21]. The accuracy of information on income levels may be questionable in many communities, making comparison difficult.

Intensive physical activity was associated with favorable lipid profiles in this study. Intervention studies have demonstrated improvements in lipid profile with increases in exercise [19-21], as physical activity mainly results in a reduction in triglyceride levels and an increase in HDL-C [25]. Dyslipidemia was significantly associated with co-morbidity from obesity, diabetes, and hypertension in this study. The term "secondary dyslipidemia" was used if the dyslipidemia followed a primary cause. It is difficult to assess cause and effect in crosssectional studies such as this one; obesity was significantly associated with dyslipidemia in previous national, regional, and international studies [5-8,16-28]. Hypertension was previously associated with HDL-C, TC/HDL-C, and triglycerides even after the exclusion of obesity, diabetes, and smoking [31,32]. In diabetic individuals, significantly more dyslipidemia was observed [21,33].
This study did not detect significant associations that depended on dietary habits such as fruit/vegetable consumption. However, several other lifestyle factors have been shown to be related to lipid levels in adults, including dietary habits and the intake of certain foods. [26-29,34].

\section{Conclusion}

Hyperlipedimia is increasing at fast pace and reaching higher prevalence rates in KSA. This finding suggests that metabolic syndrome may represent a major health problem. There is an urgent need for a multisectorial intervention plan targeting identified predictors and other significant risk factors should gain more attention in any integrated and comprehensive intervention strategy aiming at prevention, control, early detection and prompt proper management. In the meantime reduction of obesity rates by increasing the public awareness of importance of adopting healthy eating habits, and increasing physical activity are of paramount importance to reduce dyslipidemia incidences.

\section{Acknowledgements}

This study was supported and supervised by the Ministry of Health-KSA and the WHO-EMR Office-Egypt.

\section{Authors' Contributions}

Al-Hamdan conceived, designed, overviewed data collection and implemented the study and provided critical academic insight. Al-Kabbaa wrote the first draft and subsequent revisions of the manuscript; Saeed provided academic inputs, contributed to the first draft of the article and revisions; Hamza and El Taher helped in handling the data and analyses and overlooked biochemical measurements. Abdulshakour helped in data collection and analysis and helped in data analyses. All authors jointly conceived, designed and overviewed data collection, provided statistical inputs and participated in writing of the article. All authors have read and approved the final manuscript.

\section{Study Limitations}

The study is cross-sectional and hence it is difficult to assess properly etiological factors of dyslipidemia. The study included only subjects in age group $15-6$ years of age. Other factors which could be associated with dyslipidemia such as drugs were not included.

\section{REFERENCES}

[1] World Health Organization, "Quantifying Selected Major Risks to Health," World Health Organization, Geneva, 
2002.

[2] D. Smith, "Epidemiology of Dyslipidemia and Economic Burden on the Healthcare System," American Journal of Managed Care, Vol. 13, No. S3, 2007, pp. S68-S71.

[3] J. Stamler, M. L. Daviglus, D. B. Garside, A. R. Dyer, P. Greenland, et al., "Relationship of Baseline Serum Cholesterol Levels in 3 Large Cohorts of Younger Men to Long-Term Coronary, Cardiovascular, and All-Cause Mortality and to Longevity," The Journal of the American Medical Association, Vol. 284, No. 3, 2000, pp. 311-318. doi:10.1001/jama.284.3.311

[4] WHO, "Country Cooperation Strategy for WHO and Saudi Arabia 2006-2011,” 2012.

http://www.who.int/countryfocus/cooperation_strategy/cc s_sau_en.pdf

[5] M. M. Al-Nozha, M. R. Arafah, M. A Al-Maatouq, M. Z. Khalil, N. B. Khan, K. Al-Marzouki, Y. Y. Al-Mazrou, M. Abdullah, A. Al-Khadra, S. S. Al-Harthi, M. S. Al-Shahid, A. Al-Mobeireek and M. S. Nouh, "Hyperlipidemia in Saudi Arabia," Medical Journal, Vol. 29, No. 2, 2008, pp. 282-287.

[6] D. O. Ogbeide, A. Karim, I. M. Al-Khalifa and S. Siddique, "Population Based Study of Serum Lipid Levels in Al-Kharj Health Center, Saudi Arabia," Saudi Medical Journal, Vol. 25, No. 12, 2004, pp. 1855-1857.

[7] S. N. Al-Shehri, Z. A. Saleh, M. M. Salama and Y. M. Hassan, "Prevalence of Hyperlipidemia among Saudi School Children in Riyadh," Annals of Saudi Medicine, Vol. 24, No. 1, 2004, pp. 6-8.

[8] B. A. Abalkhail, S. Shawky, T. M. Ghabrah and W. A. Milaat, "Hypercholesterolemia and 5-Year Risk of Development of Coronary Heart Disease among University and School Workers in Jeddah, Saudi Arabia," American Journal of Preventive Medicine, Vol. 31, No. 4, 2000, pp. 390-395. doi:10.1006/pmed.2000.0713

[9] R. Bonita, M. de Courten, T. Dwyer, K. Jamorzik and R. Winkelmann, "Surveillance of Risk Factors for NonCommunicable Diseases," The WHO Stepwise Approach, WHO, 2001.

[10] WHO, EMRO, "STEPwise WHO,” 2005. http://www.who.int/chp/steps/2005_Saudi Ara bia_STEPS_Report_EN.pdf

[11] W. T. Friedewald, R. I. Levy and D. S. Frederickson, "Estimation of the Concentration of Low-Density Lipoprotein Cholesterol in Plasma, without Use of the Preparative Ultracentrifuge," Journal of Clinical Chemistry, Vol. 18, No. 6, 1972, pp. 499-502.

[12] Expert Panel on Detection, Evaluation, and Treatment of High Blood Cholesterol in Adults, "Executive Summary of the Third Report of the National Cholesterol Education Program (NCEP) Expert Panel on Detection, Evaluation, and Treatment of High Blood Cholesterol in Adults (Adult Treatment Panel III)," The Journal of the American Medical Association, Vol. 285, No. 19, 2001, pp. 2486-2497. doi:10.1001/jama.285.19.2486

[13] H. Saadi, S. G. Carruthers, N. Nagelkerke, et al., "Prevalence of Diabetes Mellitus and Its Complications in a Population-Based Sample in Al-Ain, United Arab Emirates," Diabetes Research and Clinical Practice, Vol. 78,
No. 3, 2007, pp. 369-377. doi:10.1016/j.diabres.2007.04.008

[14] R. T. Jackson, Z. Al-Mousa, M. Al-Raqua, P. Prakash and A. N. Muhanna, "Multiple Coronary Risk Factors in Healthy Older Kuwaiti Males," European Journal of Clinical Nutrition, Vol. 56, No. 8, 2002, pp. 709-714. doi:10.1038/sj.ejcn.1601379

[15] S. Al-Moosa, S. Allin, N. Jemiai, J. Al-Lawati and E. Mossialos, "Diabetes and Urbanization in the Omani Population: An Analysis of National Survey Data," $\mathrm{Po}_{0}$ pulation Health Metrics, Vol. 4, No. 5, 2006, p. 5. doi:10.1186/1478-7954-4-5

[16] A. Bener, M. Zirie, I. M. Janahi, O. A. Al-Hamaq and M. Musallam, "Prevalence of Diagnosed and Undiagnosed Diabetes Mellitus and Its Risk Factors in a Population Based Study of Qatar," Diabetes Research and Clinical Practice, Vol. 84, No. 1, 2009, pp. 99-106. doi:10.1016/j.diabres.2009.02.003

[17] Y. S. Khader, A. Batieha, M. El-Khateeb, M. Al Omari and K. Ajlouni, "Prevalence of Dyslipidemia and Its Associated Factors among Jordanian Adults," Journal of Clinical Lipidology, Vol. 4, No. 1, 2010, pp. 53-58. doi:10.1016/j.jacl.2009.12.004

[18] C. Pongchaiyakul, P. Hongsprabhas, V. Pisprasert and C. Pongchaiyakul, "Rural-Urban Difference in Lipid Levels and Prevalence of Dyslipidemia: A Population-Based Study in Khon Kaen Province, Thailand," Journal of the Medical Association of Thailand, Vol. 89, No. 11, 2006, pp. 1835-1844.

[19] W. H. Zhao, J. Zhang, Y. Zhai, Y. You, Q. Q. Man, et al., "Blood Lipid Profile and Prevalence of Dyslipidemia in Chinese Adults," Biomedical and Environmental Sciences, Vol. 20, No. 4, 2007, pp. 329-335.

[20] W. M. Kang, J. S. Zhang, X. X. Liu, M. S. Wang and M. L. Zhao, "Prevalence of Abnormity of Blood Lipid and Associated Factors in Health Examination Population in Beijing," Chinese Medical Sciences Journal, Vol. 24, No. 3, 2009, pp. 142-146. doi:10.1016/S1001-9294(09)60078-X

[21] C. Erem, A. Hacihasanoglu, O. Deger, et al., "Prevalence of Dyslipidemia and Associated Risk Factors among Turkish Adults: Trabzon Lipid Study," Endocrine, Vol. 34, No. 1-3, 2008, pp. 36-51. doi:10.1007/s12020-008-9100-Z

[22] F. Azizi, M. Rahmani, A. Ghanbarian, H. Emami, P. Salehi, P. Mirmiran and N. Sarbazi, "Serum Lipid Levels in an Iranian Adults Population: Tehran Lipid and Glucose Study," European Journal of Epidemiology, Vol. 18, No. 4, 2003, pp. 311-319. doi:10.1023/A:1023606524944

[23] R. W. Mahley, K. E. Palaoglu, Z. Atak, J. Dawson-Pepin, A. M. Langlois, V. Cheung, H. Onat, P. Fulks, L. L. Mahley, F. Vakar, S. Ozbayrakc1, O. Gokdemir and W. Winkler, "Turkish Heart Study: Lipids, Lipoproteins, and Apolipoproteins," The Journal of Lipid Research, Vol. 36, No. 4, 1995, pp. 839-859.

[24] V. Grabauskas, I. Miseviciene, J. Klumbiene, J. Petkeviciene, Z. Milasauskiene, A. Plieskiene and L. Margeviciene, "Prevalence of Dyslipidemias among Lithuanian 
Rural Population (CINDI Program)," Medicina (Kaunas), Vol. 39, No. 12, 2003, pp. 1215-1222.

[25] E. Polychronopoulos, D. B. Panagiotakos and A. Polystipioti, "Diet, Lifestyle Factors and Hypercholesterolemia in Elderly Men and Women from Cyprus," Lipids in Health and Disease, Vol. 4, No. 17, 2005, pp. 1-7. doi:10.1186/1476-511X-4-17

[26] L. J. de Souza, J. T. Souto Filho, T. F. de Souza, et al., "Prevalence of Dyslipidemia and Risk Factors in Campos dos Goytacazes, in the Brazilian State of Rio de Janeiro," Arquivos Brasileiros de Cardiologia, Vol. 81, No. 3, 2003, pp. 249-264.

[27] R. Pradeepa, R. Deepa, S. S. Rani, G. Premalatha, R. Saroja and V. Mohan, "Socioeconomic Status and Dyslipidaemia in a South Indian Population: The Chennai Urban Population Study (CUPS 11)," National Medical Journal of India, Vol. 16, No. 2, 2003, pp. 73-78.

[28] S. Wang, L. Xu, J. B. Jonas, Q. S. You, Y. X. Wang, et al., "Prevalence and Associated Factors of Dyslipidemia in the Adult Chinese Population," PLoS One, Vol. 6, No. 3, 2011, p. e17326. doi:10.1371/journal.pone.0017326

[29] R. W. Mahley, S. Can, S. Ozbayrakci, T. P. Bersot, S. Tanir, K. E. Palaoglu and G. M. Pepin, "Modulation of High-Density Lipoproteins in a Population in Istanbul, Turkey, with Low Levels of High-Density Lipoproteins," American Journal of Cardiology, Vol. 96, No. 4, 2005, pp. 547-555. doi:10.1016/j.amjcard.2005.04.018
[30] J. Yarnell, S. Yu, E. McCrum, D. Arveiler, B. Hass, J. Dallongeville, M. Montaye, P. Amouyel, J. Ferrieres, J. B. Ruidavets, A. Evans, A. Bingham, P. Ducimetiere and PRIME Study Group, "Education, Socioeconomic and Lifestyle Factors, and Risk of Coronary Heart Disease: The Prime Study," International Journal of Epidemiology, Vol. 34, No. 2, 2005, pp. 268-275. doi:10.1093/ije/dyh267

[31] Z. R. Guo, X. S. Hu, M. Wu, M. H. Zhou and Z. Y. Zhou, "A Prospective Study on the Association between Dyslipidemia and Hypertension," Chinese Journal of Epidemiology, Vol. 30, No. 6, 2009, pp. 554-558.

[32] Z. H. Liu, X. B. Xue and Z. Zhi, "Prevalence of Dyslipidemia and Associated Factors among the Hypertensive Rural Chinese Population," Archives of Medical Research, Vol. 38, No. 4, 2007, pp. 432-439.

[33] S. A. Grover, L. Coupal, H. Zowall, T. W. Weiss and C. M. Alexander, "Evaluating the Benefits of Treating Dyslipidemia: The Importance of Diabetes as a Risk Factor," American Journal of Medicine, Vol. 115, No. 2, 2003, pp. 122-128. doi:10.1016/S0002-9343(03)00303-6

[34] S. J. Song, J. E. Lee, H. Y. Paik, M. S. Park and Y. J. Song, "Dietary Patterns Based on Carbohydrate Nutrition Are Associated with the Risk for Diabetes and Dyslipidemia," Nutritional Research and Practice, Vol. 6, No. 4, 2012, pp. 349-356. doi:10.4162/nrp.2012.6.4.349 